\title{
Fostering Intra- and Entrepreneurship in Engineering Students
}

\section{Dr. Erin Jablonski, Bucknell University}

B.S. Biochemical Engineering 1999, Rutgers; M.S. Chemical Engineering 2001, Rutgers; Ph.D. Chemical Engineering 2002, Iowa State University; NSF Graduate Research Fellowship 1999-2002; NRC Postdoctoral Fellow at NIST 2002-2004. 


\title{
Fostering Intra- and Entrepreneurship in Engineering Students
}

\begin{abstract}
Engineers value the ability to solve problems in novel ways, the capacity to envision alternative solutions, and the knack for design. However, traditional instructional and evaluation methods may make students overly risk averse, impacting their willingness to innovate to the extent necessary to make disruptive changes to technology. Fostering an entrepreneurial spirit in engineering undergraduates may allow them to be more creative and less risk averse in their approach to solving multi-faceted, ill-defined problems. Analysis of student feedback from reflection essays, self-report attitudinal surveys, and instructor assessment in two very different courses that promote the entrepreneurial mindset through student-driven projects will be used to distill the attitudes and behaviors students value in being more creative and less risk averse.

The courses to be discussed aim to foster the development of an entrepreneurial mindset in students through posing ill-defined problems that they may fail to completely solve - and focus assessment on their approach to the process. Realizing the wisdom gained from failure and the experience of trying to get something to work only to find it is not feasible - whether it be for technical, economic, or practical reasons - is invaluable to engineering students. Because the threat of failure should not paralyze students' ability to move forward, but rather challenge them to fully engage with technical content, failing forward is proposed as a valuable component of engineering coursework. As a test-case for teaching the fail forward model, two courses have been developed, instructed and assessed with respect to how to improve students' capacity and willingness to be creative, take risks, and learn from failure.

The two courses in which the fail forward model has been implemented include an upper-level elective in entrepreneurship and a Fluid Mechanics course. In the course "Should we start this company?", students select and justify semester-long projects (unique to each group) and are challenged with demands that they know they may not meet with the understanding that they will be assessed on progress and process. Grade-focused students are initially uncomfortable taking on a project they may not complete, and with little information about how "far" they are expected to get, but over the course of a few weeks they let go of that distraction and focus on the work at hand and how they can improve their initial designs to make completion more feasible. Students value this lesson, although many characterize it as an educational struggle, but it prepares them for the reality of making decisions with incomplete information and working through design alternatives. The most rewarding part of teaching with the fail forward model, and perhaps the most valuable outcome, is building students' confidence in both their knowledge and their willingness to just give it a try.
\end{abstract}




\section{Introduction}

This paper will discuss how it might be possible to cultivate the characteristics that we most value in engineers with a pedagogical method that rewards learning from failure.

If what we value in engineers includes the ability to solve problems in novel ways, the capacity to envision alternative solutions, a "knack" for design, an intuitive understanding of feasibility, and technical skills and content knowledge, it seems that many common teaching and assessment methods are not cultivating these qualities. Unfortunately, many common pedagogical practices make students grade-obsessed strategic learners who are risk averse, unwilling to innovate, fearful of failure, uncomfortable with ill-defined problems, and develop an insular, silo mentality. It would seem that the content-knowledge pursuit is placing too much emphasis on single-solution disciplinary examples that limit opportunities for truly interdisciplinary work and creative problem solving.

In the courses described here I explore students' responses to offering open-ended projects that allow them to experience failure during the process of solving a problem or meeting a need. Part of the process of working through the open-ended projects is to provide opportunities to apply design thinking in an iterative approach to a viable solution. Because not all open-ended projects always end well, in the absence of a "finished" final product, I assess the process that students used to reach their end point and reward sound judgment while avoiding driving them back into their native risk-averse state. The instructional methods employed endeavor to encourage creativity by removing the constraints of typical courses by reducing the emphasis on grades, “right" answers, and students' perceptions of inadequate expertise or technical knowledge.

I have implemented the "Fail Forward" model in two very different project-based contexts; the classic engineering course Fluid Mechanics and a new entrepreneurship course "Should we start this company?": the theory and practice of starting a business.

In both courses students are challenged with projects that may fail at any point in the process, whether for economic, technical, or other reasons, and are asked to pivot, redesign, reorganize or otherwise rebound from the failure.

Failure is not something our students are comfortable handling, and these courses compel them to practice failure as a process from which they gain valuable knowledge and experience. The goal is to have students embrace failure as an opportunity and use the challenge as a way to deeply engage with course material.

The driving hypothesis is that students can be motivated to perform beyond their own expectations or perceived capabilities when they are pushed to confront difficult problems and work to solve them in a framework of functional discomfort. In the context of these courses, functional discomfort incentivizes learning by helping students recognize their need to know something, and leads to a self-awareness about what they can learn independently. 


\section{Fluid Mechanics: Design of a Grey-Water System}

"Why do we flush toilets with potable water?"

Over the past six years I have posed this question to the sophomore chemical engineering students in our required Fluid Mechanics course. Various facial expressions have been offered in response.

This question is meant to motivate a discussion, which eventually leads to this project statement provided to the students:

You work for an environmentally conscious campus greening consulting firm. Your project group has been hired to provide an engineering schematic and cost estimate for the optimal design of a plumbing with grey-water recovery and green roof (rain water recovery optional) system for a new residence hall on campus. Details of the building floor plan, utilities, and HVAC system will be provided in a forthcoming document.

To complete this project, your team will have to investigate how residence hall plumbing is installed, propose a reasonable layout for the plumbing system, determine all the piping, couplings, fittings, drains, vents, etc., necessary for the installation, and design an appropriate grey-water system. The team will also need to gather data and statistics on typical water usage by occupant and activity. Once the details of the plumbing and grey-water system are determined, the installation costs (including materials and labor) must be estimated.

Your goals for the optimal design include (but are not limited to) minimizing pressure loss to delivery points (faucet exits) and minimizing both the quantity of fresh (city) water coming into the residence hall and that exiting to the sewer.

You have also been asked to develop a small model of a grey-water system as this is a technology that may be unfamiliar to certain stakeholders. Your goals for a $1 / 12^{\text {th }}$ scale model are to best demonstrate the plumbing and equipment necessary to effectively implement grey-water recovery/reuse with a green roof and rain water capture.

There are myriad sources of technical information about grey-water systems, rain water capture, and green roof installations available online and in trade publications. Your group will need to consider case-by-case scenarios to determine the best system for this residence hall.

Your report should be written in a standard technical report format and include cost estimates in the form of a budget (vendor quotes may be included when appropriate). Online resources are available. Based on cost savings from 
decreased water and sewer use, calculate a time to pay back on the initial investment and provide an economic justification for implementation of your system.

Consultations with the professor cost $\$ 1,000$ per hour. In the event that you seek advice from expert consultants other than the professor, they must be paid at a rate of $\$ 500$ per hour. You may consider consulting the experts (names of teaching assistants provided). All consulting costs must be included in your budget.

To order equipment and materials necessary to build your model you must provide a complete order sheet with justification for all components not available within the Chemical Engineering Department for review to the professor.

Students work in groups of three and typically assign each member a number of specific responsibilities. During the six weeks of this project, many students follow a path similar to the five stages of grief. In the first week, students refuse to accept that no additional information will be provided (beyond the blueprints) and are essentially in denial that they will have to direct the project without explicitly being told what they should be doing. In the second week, after realizing that they are responsible for finding the information necessary to complete the project, students are frustrated (but not quite angry) that not only do they have to find the relevant information on their own, but that they are already a week behind. By the third week students realize that they do need to seek outside help. During their solution development they experience small, localized failures that make them doubt their abilities. For example, one year a group selected copper piping for their drains, which led to exorbitant costs that made their project economically unfeasible. I requested that the group attempt to find, in any building on campus, a copper drain pipe and report back on their findings. In another instance, students neglected to vent any of the drains in their design, so I asked that they perform an experiment on water draining with and without venting to demonstrate why venting was necessary. In perhaps the most forehead-slapping incident to date, a group had designed a system where grey water was expected to drain by gravity from a shower drain on the floor to an inlet point four feet above the floor twenty feet away. Using some simple equipment in the lab (bucket, hose, funnel) I asked that they justify that scenario. Their final design showed a grey water collection tank in the basement.

After such hurdles, students typically prepare a long list of questions and arrange to meet me for consultation. At this point they know they must use the time wisely, so they resort to bargaining, either for free consultation time or for a modification of the deliverables. As the due date for the project approaches, students can become discouraged and perceive that they will not be able to complete the project because they are only novices and the task is too burdensome. At this point it is important to provide constructive coaching. Finally, in those last few days of intense work, 
students accept that they do have the skills and resources available to complete the deliverables and often produce impressive work.

The reason for assigning a value to the time students may consult with myself or other "experts" is to really make them be as resourceful as possible on their own. In no way do I deter students from seeing me in the event that something has gone very wrong in their design, but the cost on their budget makes it an option of last resort. It takes a lot of rapport-building to get students to trust that I have their best interest in mind, and I have never received feedback that this policy was perceived negatively by the students.

The outcomes of the project are a professional presentation given to the class and several expert visitors, a complete project report including technical and economic feasibility, and a confident group of students ready to tackle the next project. In the second half of the semester they are given a completely open ended design project where each group is assigned a unique technical issue that they must construct an apparatus to test or address. Using a similar process to the first project students are coached through the process and many of the products have actually become experiments used in the Fluid Mechanics teaching laboratory.

Anonymous feedback was obtained from the course evaluation forms. Students provided several comments related to these projects, such as:

"The open ended problems and projects helped me become familiar with what I will likely face in the real world, so I feel much more comfortable with those real world type assignments now."

"I found the problem based style of teaching to be very effective in this class. Allowing the students to learn by doing was effective particularly with this subject matter."

"The freedom of finding the answers for ourselves in many cases helped me to gain a greater understanding of the information. Rather than just being told the answer, I was forced to find the answer and understood the concepts supporting it."

"I really like the Project 1 assignment - it was cool to directly apply what we learned in class to a real-life problem. Also, I enjoyed the emphasis on having intuition about things so you can visualize systems and check if your answer makes sense."

Students' feedback regarding course goals and learning are summarized in Table 1. Generally speaking students are reporting good ratings regarding their learning in the course.

Table 1. Student Ratings of Learning for Fluid Mechanics

\begin{tabular}{|l|l|}
\hline & Rating (out of 5) \\
\hline Gaining factual knowledge (terminology, methods). & $4.5 \pm 0.8$ \\
\hline Learning fundamental principles, generalization, or theories. & $4.4+0.6$ \\
\hline $\begin{array}{l}\text { Learning to apply course materials (to improve thinking, problem solving, } \\
\text { and decisions. }\end{array}$ & $4.6 \pm 0.6$ \\
\hline
\end{tabular}




\begin{tabular}{|l|l|}
\hline $\begin{array}{l}\text { Developing specific skills, competencies, and points of view needed by } \\
\text { a professional in the field most closely related to this course. }\end{array}$ & $4.3 \pm 0.7$ \\
\hline Acquiring skills in working with others as a member of a team. & $4.4 \pm 1.0$ \\
\hline $\begin{array}{l}\text { Learning how to find and use resources for answering questions or solving } \\
\text { problems. }\end{array}$ & $4.0 \pm 0.7$ \\
\hline
\end{tabular}

There are some students who firmly resist the notion that they should be forced to be independent learners or that they should have to perform in the absence of explicit assessment of their performance (i.e., a grade). Comments relating to these issues are few; for example:

"I would prefer more lecture based or example based classes. I know many people prefer Professor Jablonski's method. I personally enjoy learning concepts and seeing a problem done once."

Overall, using the methods of problem- and project-based learning with the model of turning small failures into learning opportunities, students develop problem-solving skills that serve them well in upper level design courses and in their careers.

I have been told by students in years after the course that the grey water project was one they often spoke about during internship and job interviews, in response to interviewer questions such as "Tell me about a time that you had to learn something on your own in a short period of time" or "Tell me about a time when you had to apply knowledge from the classroom to a real-world problem." Although this is only anecdotal evidence, it points to the desirable outcomes of independent learning and ability to apply technical knowledge to solve an open-ended problem.

\section{Should we start this company?}

Using failures as teachable moments and coaching students to persist in the face of setbacks are fundamental to helping students develop an entrepreneurial mindset. Should we start this company? is essentially a student-project centered course in entrepreneurship, generating new business ideas, and technological product or service design and development through business planning. Students have to identify a customer base and do market research, including surveying if appropriate. Stretch goals for student-driven projects include proposals for expanding capabilities of the product or service, optimizing production or delivery, and identification of new market share. The culmination of the course is to present the groups' business ideas to investors and judges (in a business pitch competition), and use feedback and knowledge gained from these presentations to make a final report including an analysis of the businesses' potential for success.

The guiding principle in designing this course was that modeling the process of ideation, research, development and commercialization in a course environment would foster an 
entrepreneurial spirit in engineering undergraduates; making them less risk-averse and more creative and open-minded in their approach to solving multi-faceted, ill-defined problems.

There are some issues to resolve in applying the Fail Forward model in this entrepreneurship course. Because the course is open to a broad range of majors, students work in groups (of typically 4-5 students) where motivations and perspectives differ widely. Thus, individual accountability must be explicit and emphasized in the course assessment scheme. Grade-focused students have difficulty with the frequency and informality of the feedback provided because they want numerical scores in order to gauge their progress in the course. Courses that are perceived by the students to be risky also require a lot of the instructor - to maintain a positive environment in the face of failure by rewarding students' willingness to try, and to develop a path through the course that builds confidence through a series of small, meaningful victories.

"Should we start this company?" is unique because it is cross-listed in the College of Engineering, in the School of Managements (as a Markets, Innovation, and Design course), and as a university course. As a result the course is a mix of about one third engineers (of all disciplines), one third management students (typically marketing focused), and one third economics, with a few valuable wildcards, such as majors in psychology, art, and environmental studies. The combination of students brings diverse perspectives and expertise to the course. The enrollment is 30 students or more.

This course meets one per week for three hours as a whole class, and after the first week each group is required to meet with me for one hour outside of class. Before the first class meeting time students are expected to complete a course blog post telling a little about themselves and why they chose to take the course. This practice gets them into the habit of completing the frequent blog prompts that are used to keep students engaged with the course even though we only meet as a group formally one each week.

In the first class they get a crash course from our Small Business Development Center regarding how to establish a business, how to write a business plan, and how to prepare the related financial documents. I do this up front because I want students to know what to expect regarding the major deliverable of the course and give them the option to drop the course if it does not match their expectation.

In the second class, I go through an ideation process of problem identification / opportunity recognition, and then do a modified version of speed dating so that the students get to meet each other and hear about all the ideas generated. By the end of this class groups pitch the best idea and seek feedback from their peers. They also blog about these initial business ideas and other students in the course provide feedback. More often than not the feedback from this first week leads to their first failure - and students go back to the ideation process to come up with a new business idea. 
In nearly every subsequent week of the course entrepreneurs are invited to speak about their experiences in start-up projects, followed by an extensive discussion with the students seeking feedback about their own ideas. At any point in the first half of the semester a group may decide that their idea for a business is no longer worth pursuing and they have the option to change their idea, dissolve the group and be hired onto other groups moving forward, or to do some combination of self-reorganization that gets every student working on a project in which they feel invested. Each project is given its own page on the course blog, and students are expected to post at least once per week regarding progress on their project.

In the eighth week of a fourteen week semester, there is a university-wide Business Pitch competition. Participation in the qualifying round for this event is a requirement of the course. In a subsequent week the class attends the finals of the competition, both those who qualified and those who did not, and all are asked to comment about what makes a good pitch, and how this experience has changed how they talk about their product or service.

In the final weeks of the semester, when students are working to assemble the final business plan, create a video similar to those seen on a typical crowd-funding site, and preparing their final presentations for the course, it is a time of intense activity that, added to the feedback from the business pitch competition, leads to improvements in the students' designs, implementation plans, marketing strategy, etc.

In anonymous responses to the prompt, "What elements of the course and instruction did you find most helpful for accomplishing the course's learning goals?", students provided comments such as:

"Having two different projects and the ability to move around was helpful. It allowed me to take risks and if a business idea turned out to be a bad idea after spending time on it, we were not stuck with it."

"The freedom to pursue an idea and learn about entrepreneurship in context."

"The professors continued motivation and drive that kept our group moving forward."

"The class was extremely open-ended, allowing students to fully develop their ideas and business plans."

Students' feedback regarding course goals and learning are summarized in Table 2. The goals of this course were related to developing both technical competencies and creative capacities. 
Table 1. Student Ratings of Learning for "Should we start this company?"

\begin{tabular}{|l|l|}
\hline & Rating (out of 5) \\
\hline $\begin{array}{l}\text { Learning to apply course materials (to improve thinking, problem solving, } \\
\text { and decisions. }\end{array}$ & $4.0 \pm 0.9$ \\
\hline $\begin{array}{l}\text { Developing specific skills, competencies, and points of view needed by } \\
\text { a professional in the field most closely related to this course. }\end{array}$ & $4.0+0.9$ \\
\hline Acquiring skills in working with others as a member of a team. & $4.4 \pm 0.8$ \\
\hline $\begin{array}{l}\text { Developing creative capacities (writing, inventing, designing, etc.) } \\
\text { Learning how to find and use resources for answering questions or solving } \\
\text { problems. }\end{array}$ & $4.1 \pm 1.1$ \\
\hline $\begin{array}{l}\text { Acquiring an interest in learning more by asking questions and seeking } \\
\text { answers. }\end{array}$ & $3.9 \pm 0.9$ \\
\hline
\end{tabular}

There were also student comments that indicate that some student groups had trouble with the self-directed component of the course, or were unable to recover from failure as easily. These are the types of comments I hope to see less of as the course is refined in subsequent offerings:

"I prefer a bit more overall organization, but I did like the flexibility involved especially around the pressures of creating businesses."

"Create more concrete deadlines - this will encourage people to actually work on their business plans."

Student essay responses indicate a near unanimous satisfaction with the course pushing their creative abilities and being unique from other courses they have taken. However, the essays also highlight particular points of discomfort. Some students want to be "walked through" the stepby-step process of building a business plan. I do not think this would serve them well, because each business idea is unique. Rather, in individual group meetings I provide extensive feedback on their drafts. What makes them most uncomfortable is the aspect of failure late in the semester. Fortunately by that point many groups are able to modify their core idea rather than totally drop it and start over.

\section{Summary}

In two project-based courses I have attempted to implement a system whereby students are formally encouraged to learn from failure, and are assessed on the process that they use to reach their final deliverable and, importantly, on the means they use to justify decisions that are made within that process. The open-ended, no-one-right-answer projects that are assigned with little given information provide students myriad opportunities to mature in their technical expertise, problem-solving, and resourcefulness. 
Teaching this way can be more time intensive for an instructor; individual weekly meetings with each project group often double the time commitment of the traditional course. Also, to move away from numerical or letter grade emphasis means that feedback is provided as substantial text regarding their project progress and decision justification. It is also a challenge to let students discover things for themselves, because although there may not be one right answer, there may be a very short path to a solution of an intermediate problem that, if revealed, would rob the students of the opportunity to develop their own reasoning skills and intuition.

\section{References}

There are hundreds of books and articles related to the topics of student motivation, student risk aversion, strategic learning, fostering creativity and design thinking, and the role that instructors play in nurturing or quashing desirable traits in students. Efforts to continuously inform my pedagogical technique are based on documented best practices and new information about how students and academia are changing.

Costa, A. \& Kallick, B. (2008). Learning and Leading with Habits of Mind: 16 Essential Characteristics for Success. Association for Supervision \& Curriculum Development. Print.

"Risk averse students characterized by high abilities tend to prefer Engineering." quoted from: De Paola, M. \& Gioia, F. Risk Aversion and Field of Study Choice: the Role of Individual Ability. Bulletin of Economic Research, 64(1), p. s193-s209, December 2012.

Genco, N.; Hölttä-Otto, K.; Seepersad, C.C. An Experimental Investigation of the Innovation Capabilities of Undergraduate Engineering Students. Journal of Engineering Education, 101(1), p. 60-81, January 2012.

Kelley, T. \& Kelley, D. (2013). Creative Confidence: Unleashing the Creative Potential Within Us All, New York, NY: Crown Business.

Wilbur, R. (2013). Boxed In: The Lack of Creative Thinking in Engineering Students. Retrieved Mar 30, 2104 from https://digarchive.library.vcu.edu/handle/10156/4415 